\title{
Research Paper \\ Comparison of Food Security Villagers With Different Attitude and Nutritional Culture in Three Zones of Climate South of Kerman Province
}

\author{
*Samira Behroozeh ${ }^{1}$, Mansoor Shahvali ${ }^{2}$ \\ 1. MSc. Department of Agricultural Extension and Education, School of Agriculture, Shiraz University, Siraz, Iran. \\ 2. Professor, Department of Agricultural Extension and Education, School of Agriculture, Shiraz University, Siraz, Iran.
}

ctitat On: Behroozeh, S., \& Shahvali, M. (2016). Comparison of Food Security Villagers With Different Attitude and Nutritional Culture in Three Zones of Climate South of Kerman Province. Journal of Rural Research. 7(3), 454-469. http://dx.doi.org/10.21859/jjr-07033

dol': http://dx.doi.org/10.21859/jjr-07033

Received: 6 Mar. 2016 Accepted: 21 May. 2016

Keywords:

Food security,

Climate, Cognitive and behavioral attitudes, Nutritional culture, Kerman

\section{A B STRACT}

Nutrition could be different in rural or urban societies. Because human nutrition on one hand is related to factors like climate, technical, socio-economic, cultural, and historical records and on the other to cognitive and behavioral attitudes of humans. This study was conducted to assess the food security situation in this region. This study was carried out to assess the food security in different climate zones of the southern province of Kerman. This study was done using applied research methodology and survey method. The study population comprised all rural households in south villages of Kerman Province. Out of them, 390 households were selected by stratified random sampling method. The data were collected by questionnaire and analyzed by SPSS 21 . Descriptive and inferential statistics were used to analyze the data. According to results, food security level was poor at the study area; while the food security situation of rural households in various parts are different. So that households of cold and mild weather regions have higher food security and after that came households of mild and hot and dry regions. This result may be due to the changing nature of agricultural production throughout the year for different areas.

\section{Extended Abstract}

\section{Introduction}

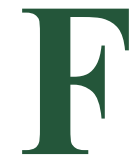

ood security is one of the most important part of social health and to creat food security there are many factors that are important such as: economic, social, political, cultural and environmental knowledge of the country we live in. In this regard, when all members of a family have enough food and enough food are available for them we can say this family have a "food security". Due to the limitation of natural and healthy food, "nutrition" and the lack of confidence to access healthy food from an acceptable way causes food insecurity and malnutrition. Human health is related to many factors like "genetic background", "climate", "sport" and "health issues". Climate change have a great impact on chronic hunger in the poorest areas. In general, food security depends on many factors, but in most previous researches about the study of nutrition in different parts of the climate zone, researchers do not enough pay attention to climate as an important factor, Therefore, the main goal of this study is to analyze the food security in different climate zones of the southern province of Kerman.

\section{* Corresponding Author:}

Samira Behroozeh, MSc.

Address: Department of Agricultural Extension and Education, School of Agriculture, Shiraz University, Siraz, Iran.

Tel: +98 (913) 8446180

E-mail: s.behroozeh@ymail.com 


\section{Methodology}

This is an applied research and it has been carried out in 2013-2014. In terms of data collection and the analysis of the data it is a descriptive research. The study population of this research included the rural households in southern Kerman province (1, 21, 849 households) and 390 households (base on Morgan table) were determined as a samples. Since the population of the study have been selected from three climate zones, "cool and moderate", "moderate" and "hot and dry", random sampling method was used with appropriate attribution. In addition, questionnaire was designed as a tools for collecting data. The validity of the questionnaire was confirmed by the presence of professors, and the reliability was conducted through a pilot test in the one of village of Bam. At the end, data from the questionnaires were analyzed by statistical software, SPSS version 21.

\section{Results}

The average age of the mothers who involved in this research was 42 years. The majority of mothers who participated in this research have a secondary education level $(36.9 \%)$ and the minority of them has diploma or over $(17 \%)$. Households in the research are divided into four groups of 1 to 3,4 to 5,6 to 7 members and more than 7 members. The most frequent categories 6 and 7 (37.2\%). According to the findings, $16.7 \%$ of heads of families have a stable job, therefore the average income of these families is 9,000,000 Rial.

The analytical data showed that the average of household food security have a significant differences in the level of 0.001 . The findings are based on scheffe test which indicated that the difference between the "cold and mild" with the "warm and dry", which is higher than cold and mild climate, while the average cognitive attitude of food security in different parts of the climate zones have a significant differences in the level of 0.001 .

In addition, the average rural household behavioral attitudes about food security in different parts of the climate zones have a significant differences in the level of 0.001 . The findings are based on Scheffe test indicated that this difference is between the "cold and mild" and two others climate zones. The average power of rural households on food security in different parts of the climate are significant differences in the level of 0.001 . So that the findings are based on Scheffe test indicated that this difference is between the climate "cold and mild" and "hot and dry", but in the cold and mild regions this difference is more.

\section{Discussion}

The current state of food security of rural households showed the differences in state of food security in different parts of the climate zones. This result may be due to the changing nature of agricultural production throughout the year for different areas. Further access to food is different between households in the areas, the food security situation in the regions has led to differences, because "climate" in the region an important role in the food security of rural households, thus the climatic conditions of each region has effect on improving their food security because, When the location is good in term of climate, it is followed by improving and expanding of agricultural conditions and many crops can be cultivated in the region. Therefore, people in the region will face a variety of products.

In this research the households based on climate conditions have an easier access to series of products that are grown and used in own areas. Meanwhile, when the variety of products have been cultivated in the region, people in the region have more knowledge about the products. Compared to areas where the climate is not possible to grow these crops, families' maybe use or not-use the rural food. This decision is important to "use" or "not-use" a food, and therefore, food insecurity and malnutrition have been occurred for rural families. So in this research, nutrition culture of rural households in different regions is different. To enjoy the food security of rural households, researcher suggests that access to a variety of food and agricultural products should be made, promoting cultivation of agricultural products.

\section{Conclusion}

According to results, food security level was poor at study area. While the food security situation of rural households in various regions is different. So that households of cold and mild regions have higher food security and after that came the households of mild, hot and dry regions. This result may be due to the changing nature of agricultural production throughout the year for different areas. 


\title{
مقايسه امنيت غذايى روستاييان با نگًرش و فرهنَ تغذيه مختلف در سه منطقه آبوهوايى جنوب استان كرمان
}

\author{
"سميرا بهروزه'، منصور شاهولى' \\ 1- كارشئاس ارشد، كروه ترويج و آموزش كشاورزى، دانشكده كشاورزى، دانشكاه شيراز، شيرازء، ايران. \\ r- استاد، كروه ترويج و آموزش كشاورزى، دانشكده كشاورزى، دائشكاه شيراز، شيرازي، ايران.
}

\begin{abstract}
حكSد

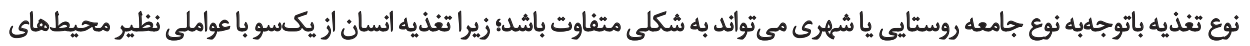

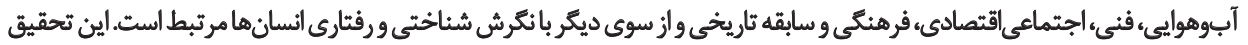

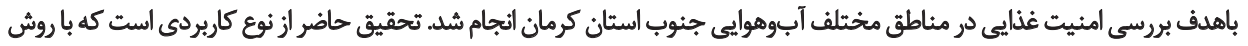

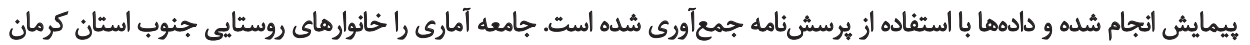

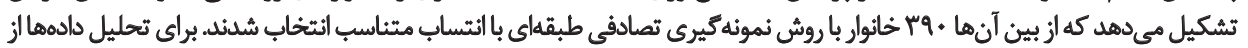

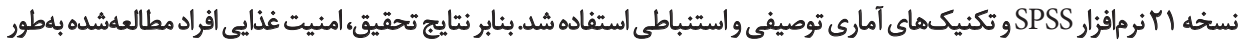

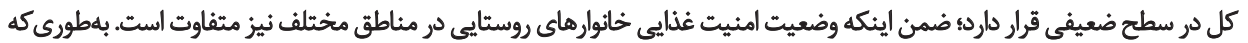

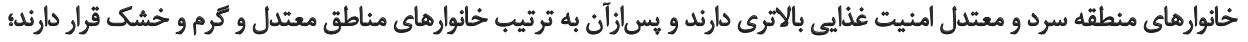

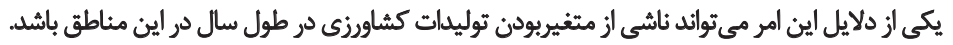

تاريخ دريافت: 19 اسيقد

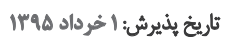

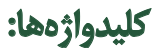

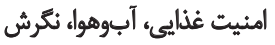
شناختى و رفتارى، فرهنك تعذيه، كرمان

نشود، بدون ترديد فرد از كمبود يوروتئين و ويتامين و مواد معدني

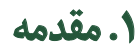

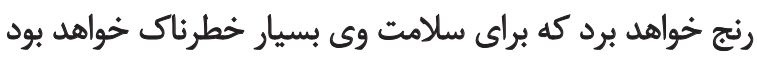

(Bakhtiari, \& Haghi, 2003).

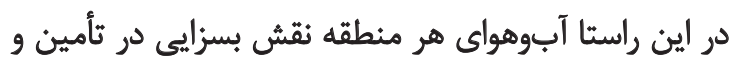

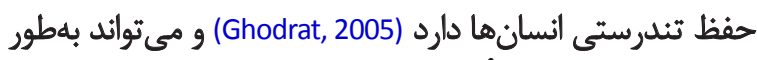

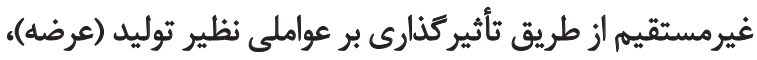

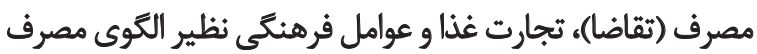

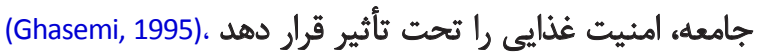

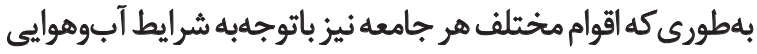

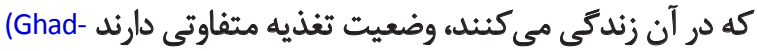

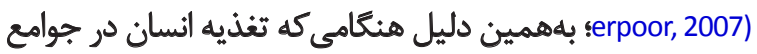

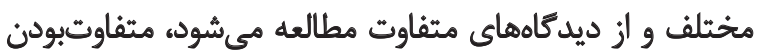

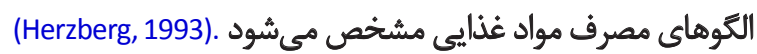

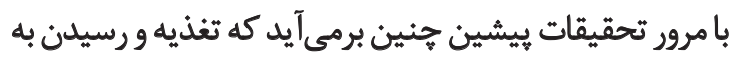

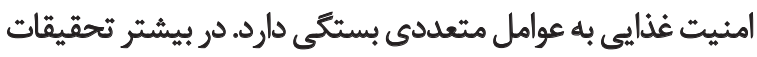

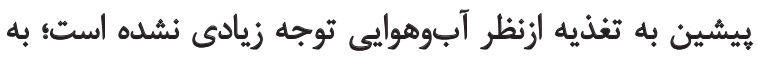

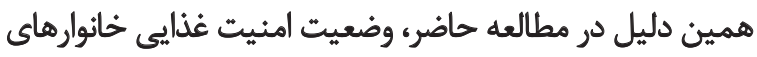

بدونترديد، امنيت غذايى در يك كشور به تدابيرى وابسته

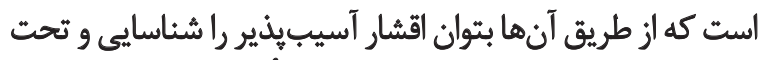

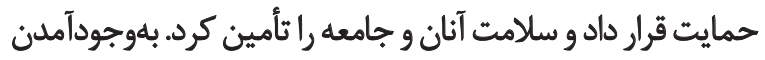

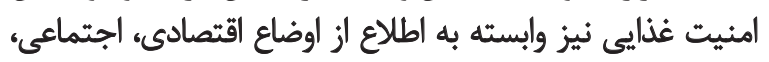

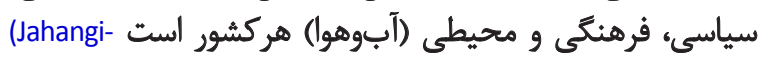

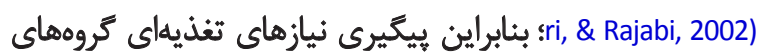

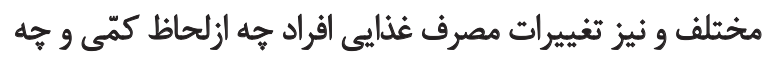

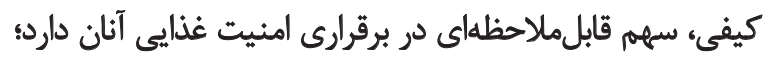

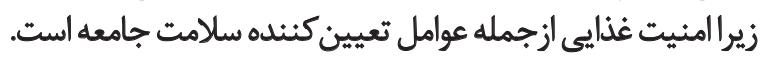

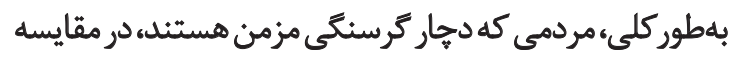

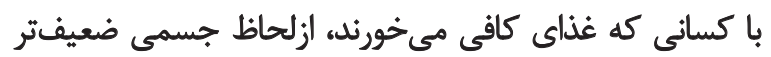

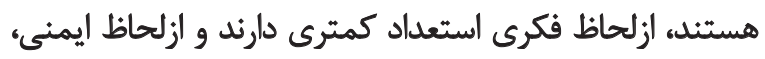

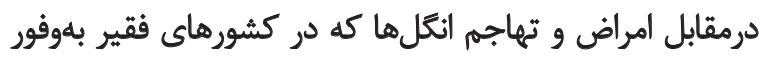

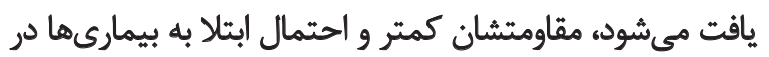

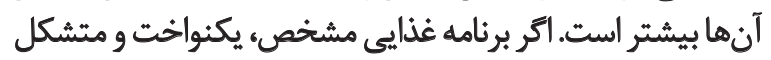

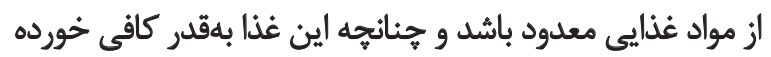

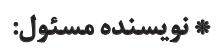

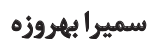

نشائي: شيرازء دانشعاه شيراز، دانشكده كشاورزى، كروه ترويج و آموزش كشاورزى.

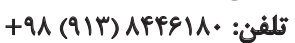

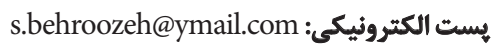




$$
\text { ديكر با نكرش شناختى و رفتارى انسانها مرتبط است. }
$$

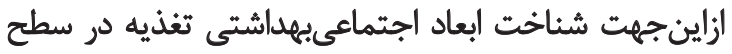

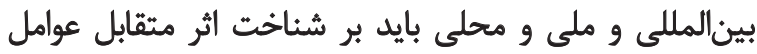

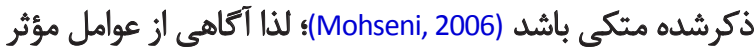

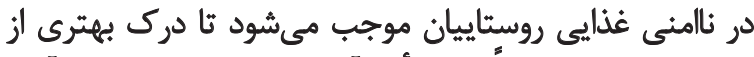

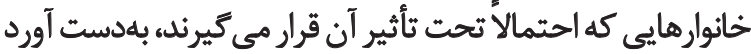
(Jahangiri \& Rajabi, 2002; Matheson, Varady, Varady, \& Killen, غذائ 2002; Ouetlette \& Wood, 1998; Galal, 2003)

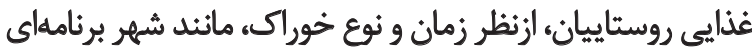

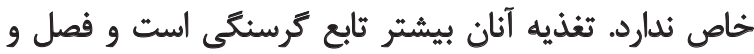

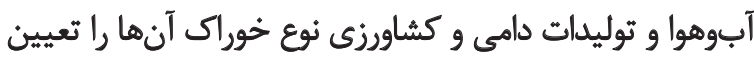

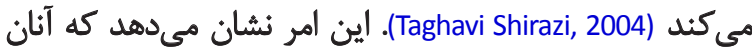

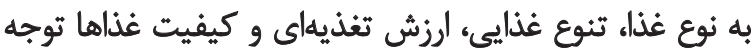
كمترى دارند (Salarkiya, Amini, Abdollahi, \& Eshrati, 2000).

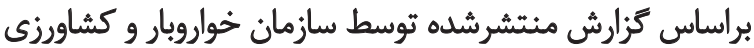

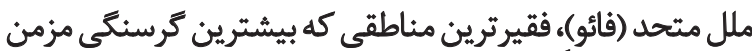

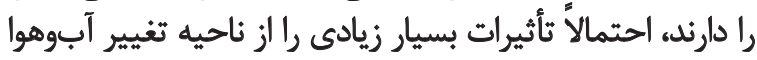
متحمل مىشوئد (FAO, 2002).

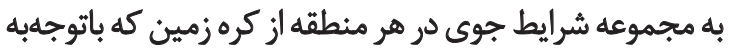

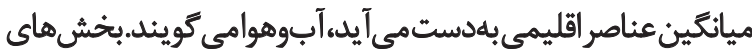

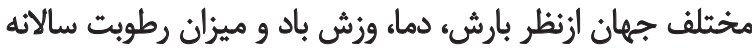

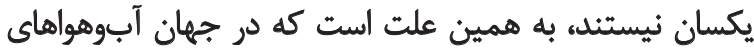

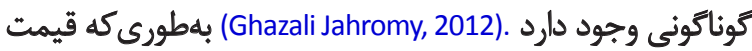

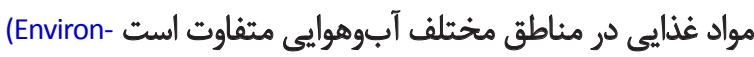

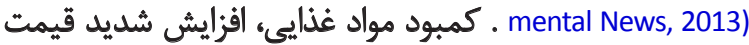

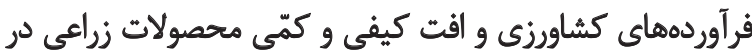

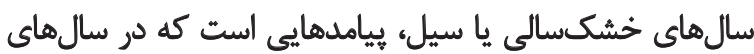
اخير در مناطق مختلف آبوهوايى ايران شاهد بودهايم - Ghahra

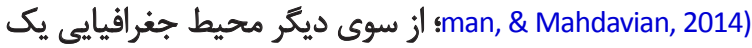
سرزمين و آبوهواى آن در شكل

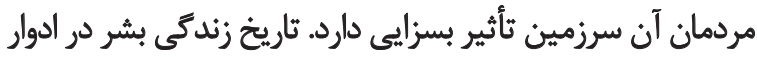

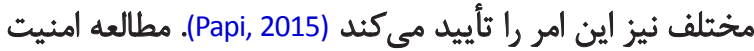

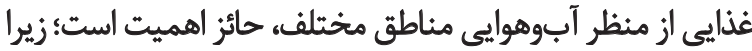

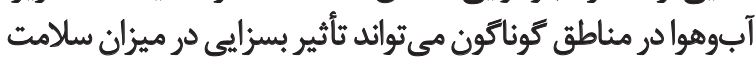
افراد داشته باشد (Ghias, et al, 2000).

منطقه مطالعهشده

منطقه مطالعهشده شامل شهرستانهاي جيرفت، عنبرآباد،

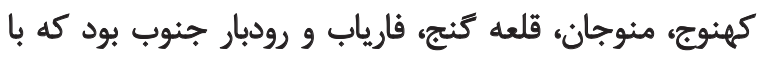

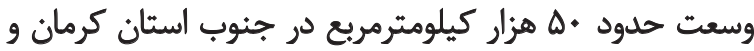
در محدوده طول جغرافيايى

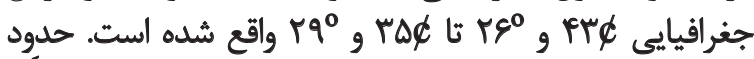

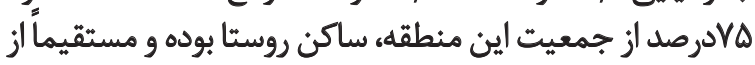

روستايى مناطق آبوهوايى جنوب استان كرمان بررسى شده

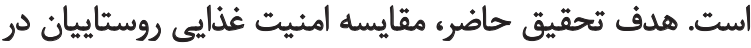

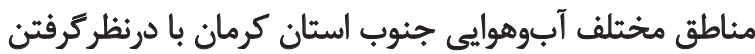

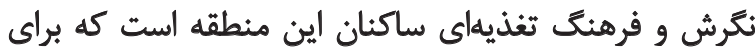

رسيدن به اين هدف برسش فرهاى تحقيق به شرح زير است: امنيت غذايى در منطقه مطالعهشده (روستاهاى جنوب استان كرمان) جِّونه است؟

وضعيت امنيت غذايى روستاييان در مناطق مختلف آبوهوايي جنوب استان كرمان به جها صورت است؟

جه تفاوتى در امنيت غذايى روستاييان مطالعهشده در مناطق مختلف آبوهوايى وجود دارد؟ امنيى جه تفاوتى ميان نترش شناختى روستاييان مطالعهشده در مناطق مختلف آبوهوايى نسبتبه مواد غذايى وجود داردي ماني جه تفاوتى ميان نترش رفتارى روستاييان مطالعهده در

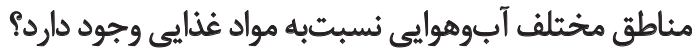
جه تفاوتى ميان فرهنك تغذيه روستاييان مطالعهشده در

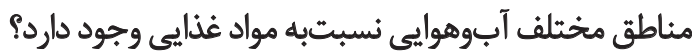

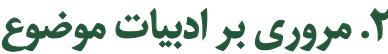

در آغاز قرن بيستهم، بسيارى از جغرافى دانان تعيين محيط

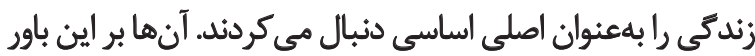

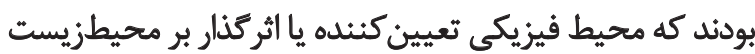

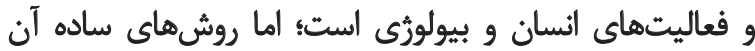

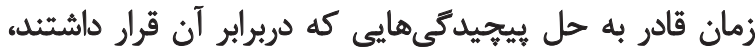

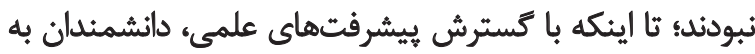

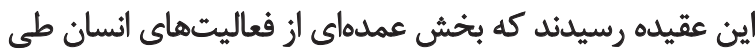

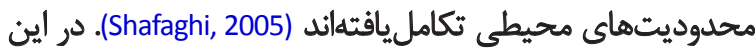

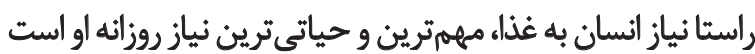

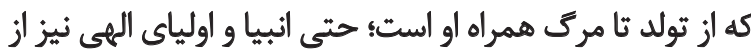
اين قاعده مستثنى نبودند (Akhondi, 2008).

يك خانوار وقتى امنيت غذايى دارد كه همه اعضاى آن براى

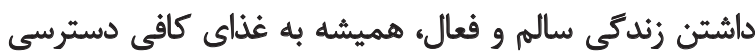

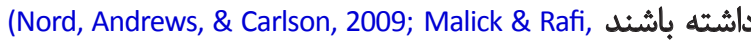

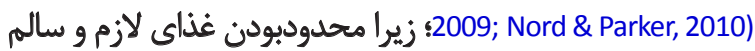

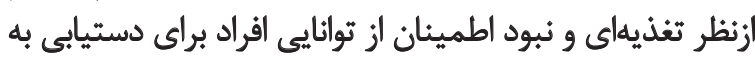

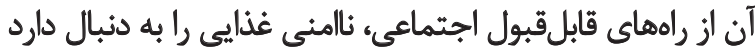

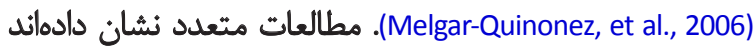

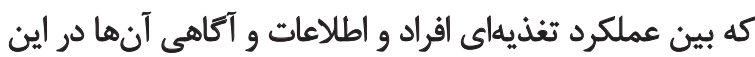

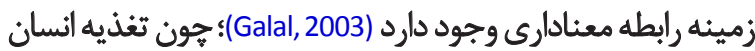

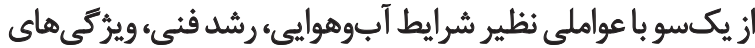

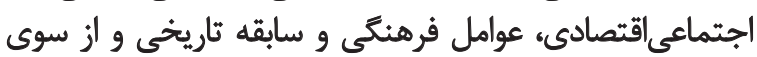


جدول ا. ويثركى هاي بارز شهرستان هاي مطالعهشده.

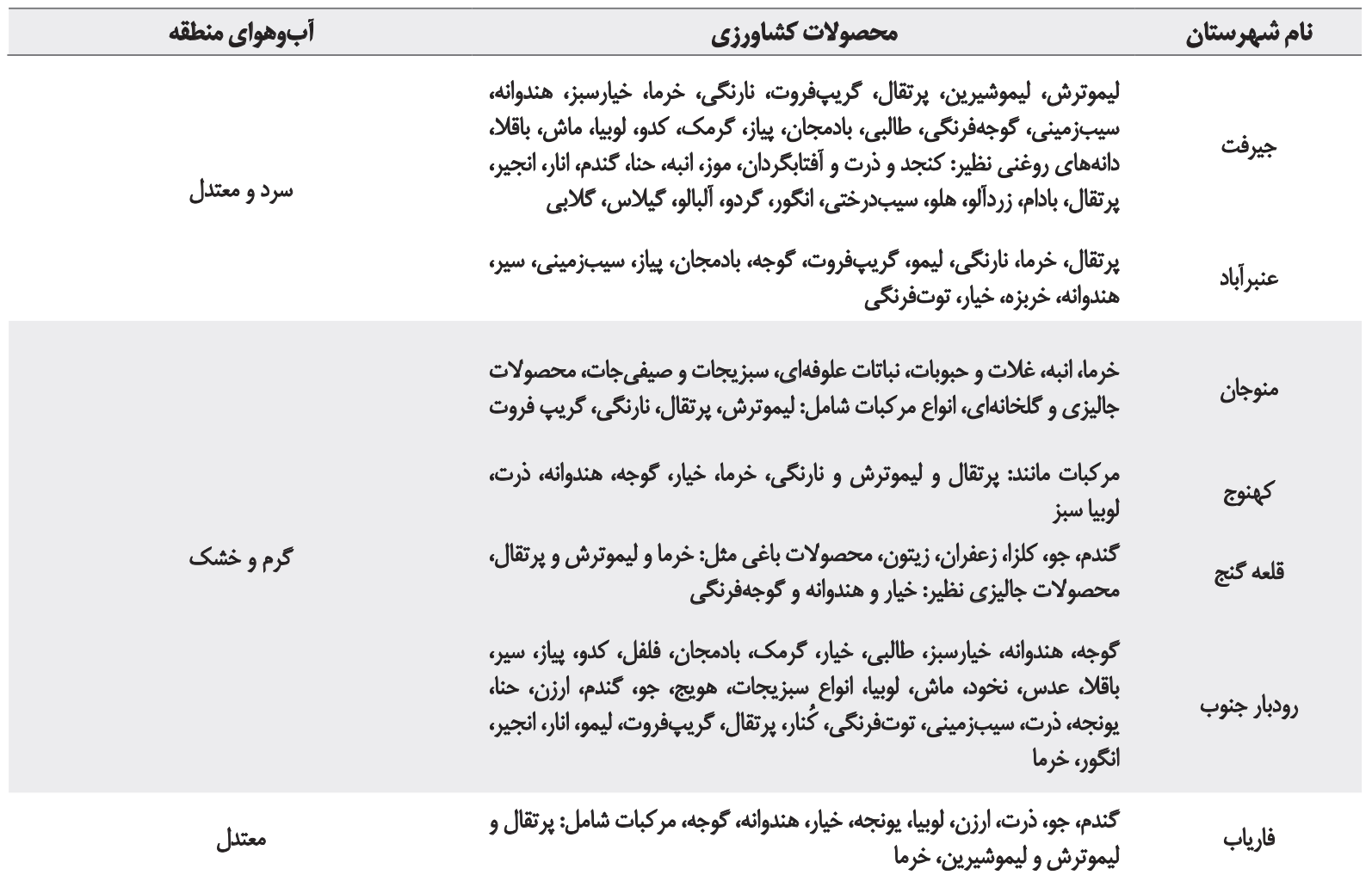

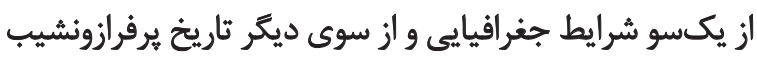

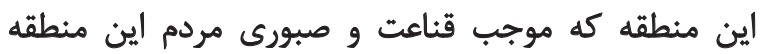

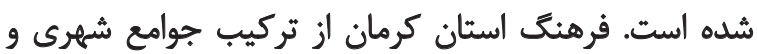

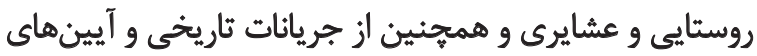

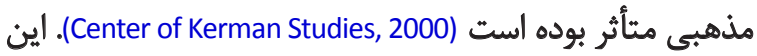
خصوصيات حاكى از آن است كه استان كرمان همانتند ديكًر

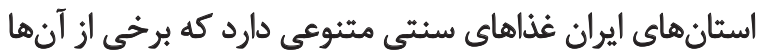

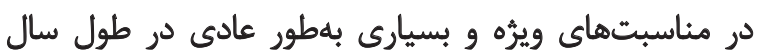

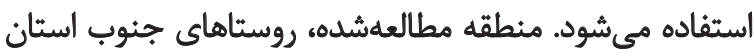

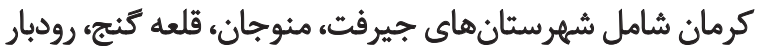

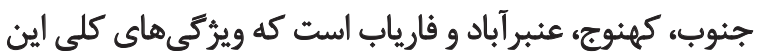
شهرستانها در جدول شماره ا آمده است.

$$
\text { راه فعاليتهاى كشاورزى و داميرورى امرارمعاش مي كردند. }
$$

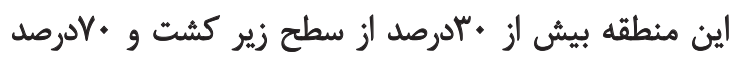

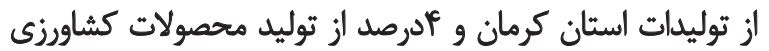

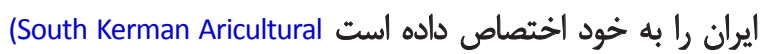
and Natural Resources Research and Education Center, 2014) و جمعيتى بالغبر يكميليون نفر دارد News Station and Analysis )

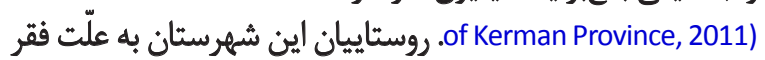

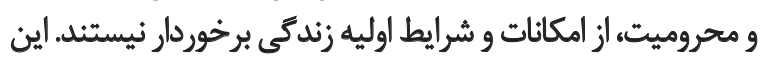

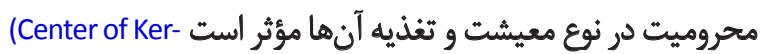
.man Studies, 2000) بهطور كلى، استان كرمان براساس دو عامل شكل كرفته است؛ جدول Y. جامعه آمارى و حجم نمونه مطالعهشده.

\begin{tabular}{|c|c|c|c|}
\hline تعداد روسيتا & حجمي نمونd & تعداد خانوار روشيثايي & منطقه آبوهواييى \\
\hline$I V \cdot F$ & in & DQTEA & سرد و معتدل \\
\hline irir & in & Dqmar & كرمو خشك \\
\hline ind & r. & VIar & 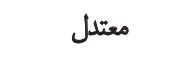 \\
\hline M.r & pq. & IrMAFq & هجموع \\
\hline
\end{tabular}


جامعه، مجموعه عادات و فرهنغ غذايى و تغذيهاى افراد آن جامعه

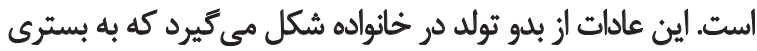

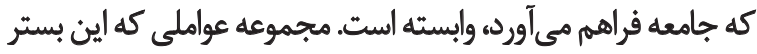

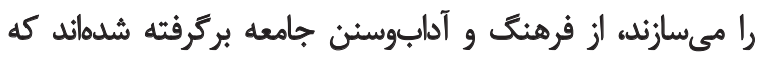

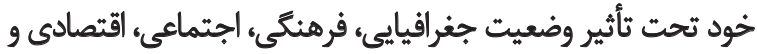

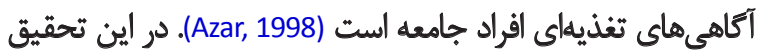

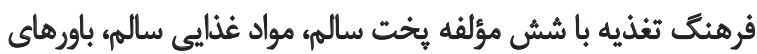

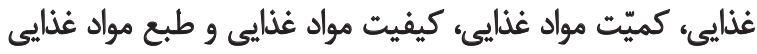

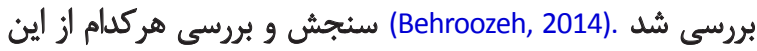

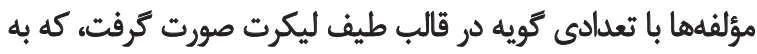

$$
\text { شرحزير است: }
$$

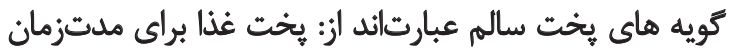

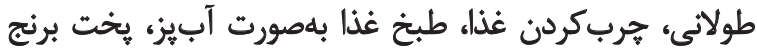

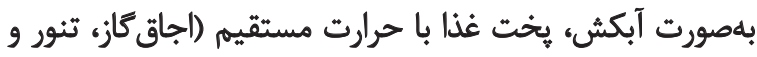

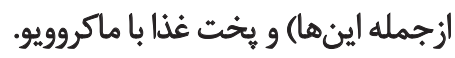

كويههاى مواد غذايى سالم عبارتاند از: استفاده از مواد منجمد

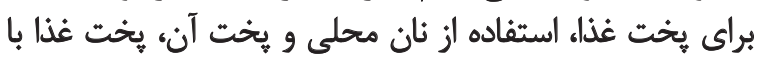

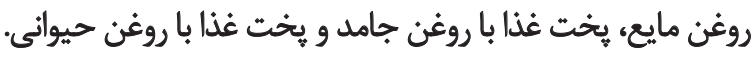
كويههاى باورهاى غذايي عبارتاند از: دفعات مصرف لبنيات،

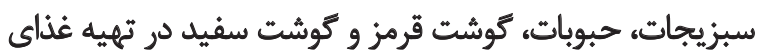

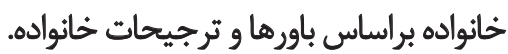

كويههاى كميّت مواد غذايى عبارتاند ازئ انتخاب نوع مواد

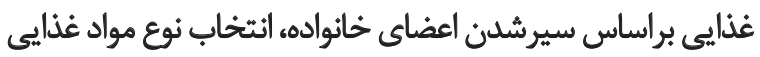

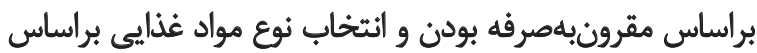
انباشتخى مواد خوراكى در خانه.

كويههاى كيفيت مواد غذايى عبارتاند از: انتخاب نوع مواد

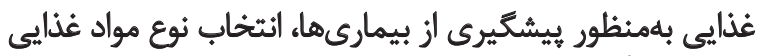

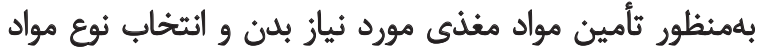

$$
\text { غذايى بلمنظور تأمين انرُّى بدن. }
$$

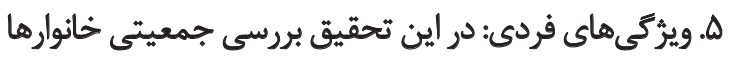

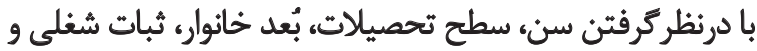

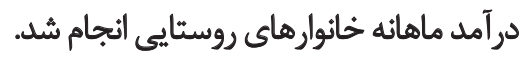

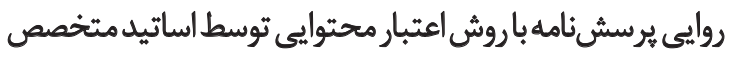

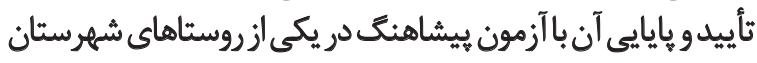

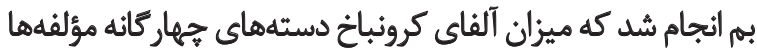

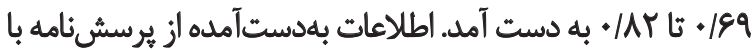

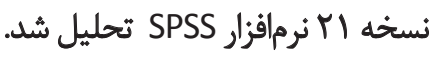

$$
\text { روش ششئاسى تحقيق }
$$

تحقيق حاضر ازنظر هدف، كاربردى و ازنظر كردآورى دادهها،

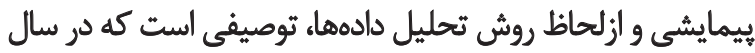

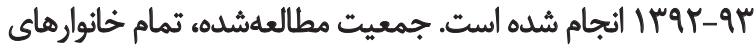

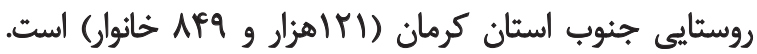

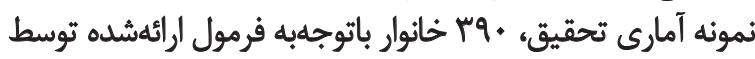

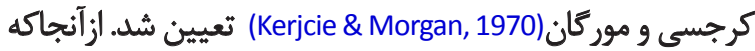

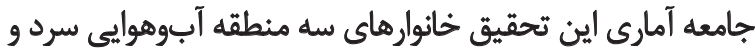

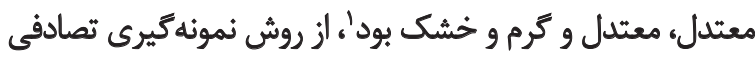
طبقهاى با انتساب متناسب طبق جدم خدول r استفاده شد.

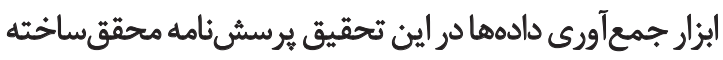

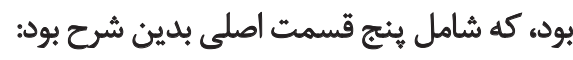

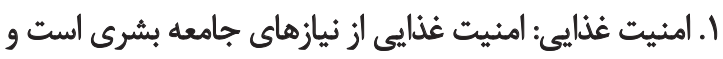

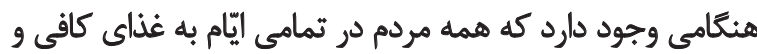

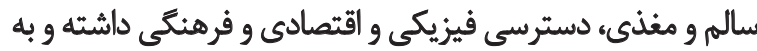

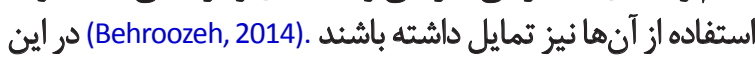

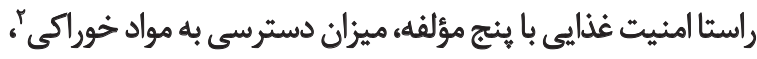

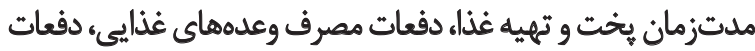

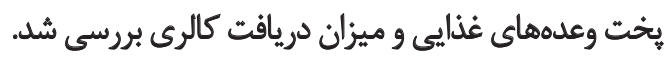

r. نكُرش شناختى: باورهايى كه شخص درباره موضوعى خاص

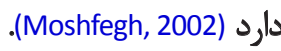

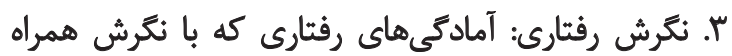

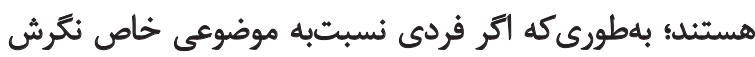

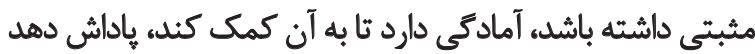

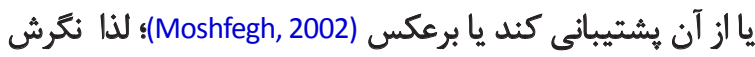

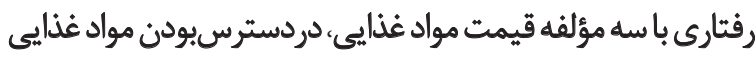
و عادت و رفتار اعضاى خانواده بررسى شد (Behroozeh, 2014). دو نكرش شناختى و رفتارى، ميزان شناخت و استفاده فرد

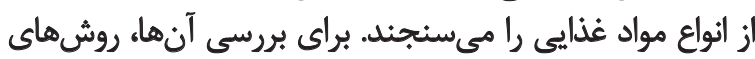

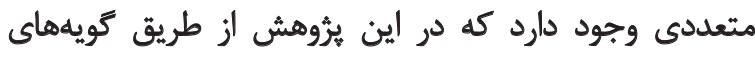

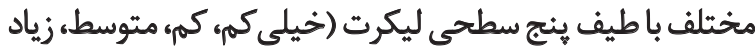

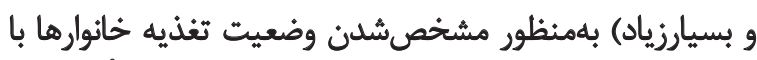

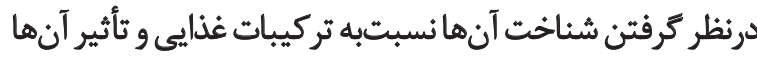

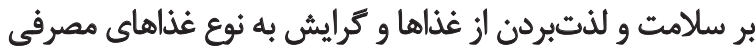

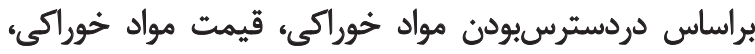

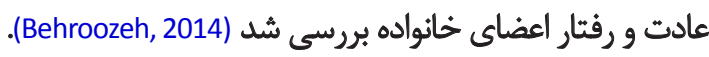

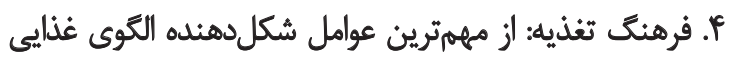


جدول r. توزيع فراوائى مؤلفههاي امثيت غذايى در خائوارهاى مطالعهشه.

\begin{tabular}{|c|c|c|c|c|}
\hline مياتئين & درصد & فراوانى & طيفها & مؤلفهها \\
\hline \multirow{5}{*}{ NHI } & i) & 18. & بسياركم & \multirow{5}{*}{ ميزان دسترسى به مواد خوراكى' } \\
\hline & rqu & 118 & كم & \\
\hline & $\mid \Delta / F$ & q. & متوسط & \\
\hline & $N T$ & $M$ & زياد & \\
\hline & $\Delta / \varepsilon$ & Mr & بسيارزياد & \\
\hline \multirow{7}{*}{ glap } & $\Delta \Delta / \mathcal{Q}$ & riv & بسياركم & \multirow{5}{*}{ ملتزمان براى بخت و تهيه غذاج' } \\
\hline & rq & III & كم & \\
\hline & $9 / V$ & ra & متوسط & \\
\hline & $\varphi / 8$ & in & زياد & \\
\hline & 1 & r & بسيارزياد & \\
\hline & $\Delta / \varphi$ & $M$ & هركز & \\
\hline & $\Delta \Delta / q$ & MIA & بهندرت & \\
\hline
\end{tabular}

NDS

$m / T$

$1 r+$

برخى مواقع

رعايت دفعات مصرف وعدههاى غذايى"

$\Delta / 4$

r)

اغلب مواقع

هميشه

هركز

بلبندرت

$1 . / 18 \quad$ ga/N

$\Delta \Delta$

برخي مواقع

دفعات يختويز وعدههاى غذايى"

IVI

TAF

انْلب مواقع

1

Vo

هميشه

$\Delta Q / V$

f

بسيارضعيف

$r \cdot / r$

MTr

ضعيف

glat

$18 / T$

ra

متوسط

وضعيت دريافت كالرى مورد نياز بلنه

$r / \&$

gr

خوب

$/ /$

1.

بسيارخوب

$r$ rep

$\Delta$

بسياركم

rVRT

189

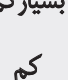

RT/TE

$9 / \Delta$

1.9

rV

متوسط

مجموع

$10 / 8$

$8)$

زياد

$\varphi / p$

IV

بسيارزياد 
ميزان دسترسى به مواد خوراكى براي بيش از نيّمى از

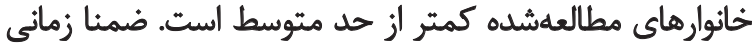

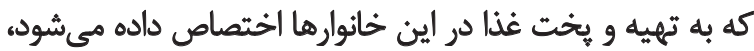

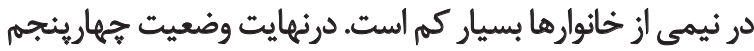

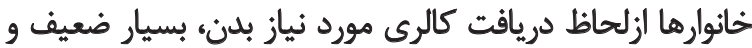

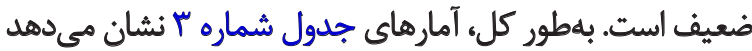

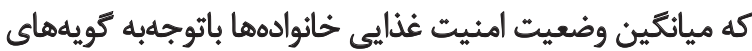

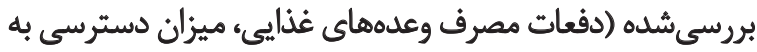

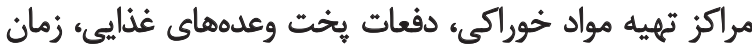

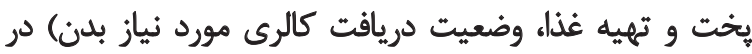

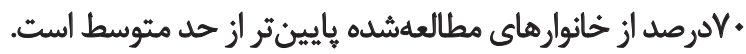

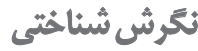

نتخرش شناختى به مواد خوراكى، باورهايى است كه شخص

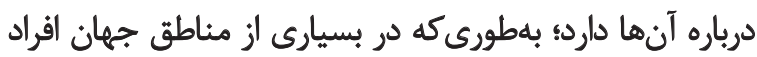

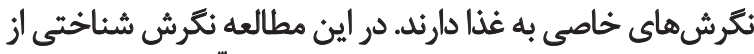

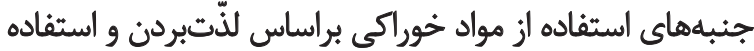

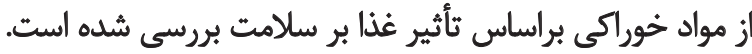

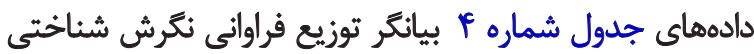

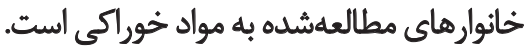
مجموع نتُرش شناختى لYدرصد از خانوارهاي مطالعهشده

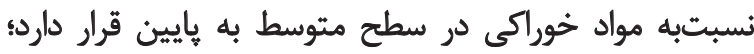

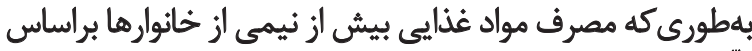

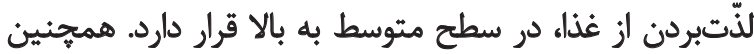

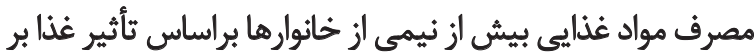
سلامت، در سطح متوسط به هايين قرار دارد.

$$
\text { نمترش رقثتارى }
$$

نكَرش رفتارى افراد به استفاده از مواد خوراكى بر بايه تمايل

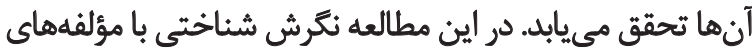

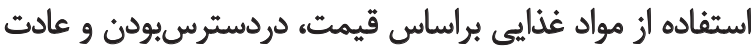

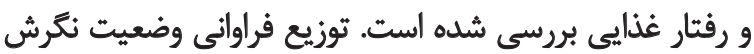

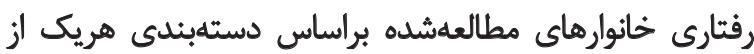
مؤلفههاى آنها بهطور كل در جدول شماره هـ آورده شده است.

هجموع نكَرش رفتاري +مدرصد از خانوارهاى مطالعهشده

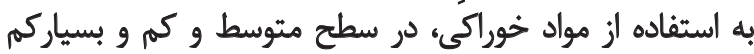

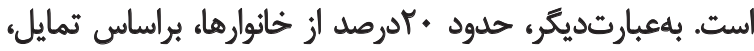

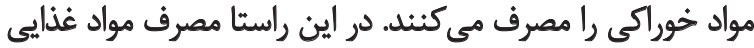

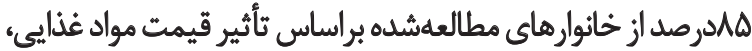

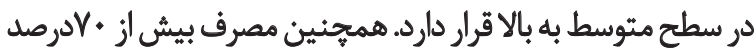

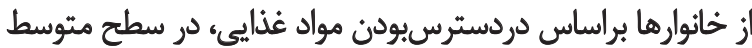

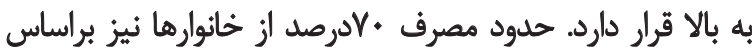

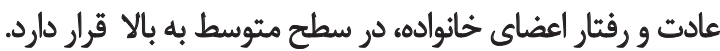

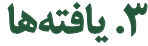

توصيفى

وضعيت سنى و تحصيلى مادران خانواده: باتوجهابه اينكه مادران

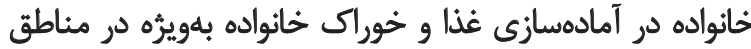

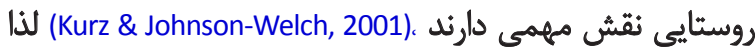

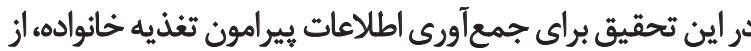

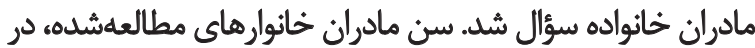

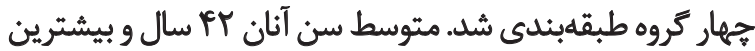

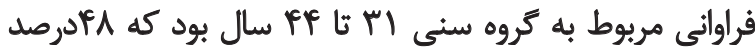

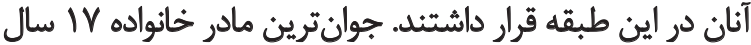

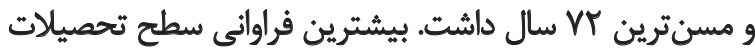

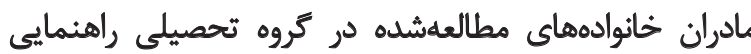

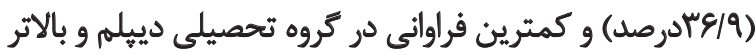

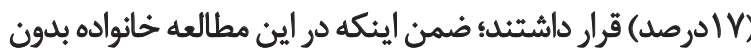

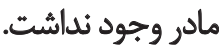

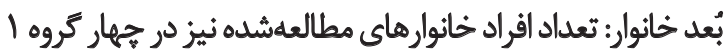

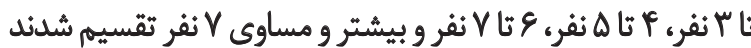

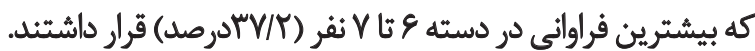

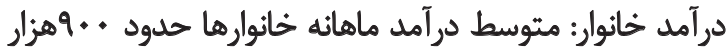

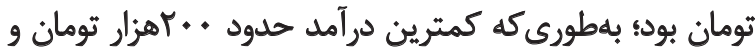

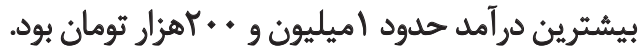

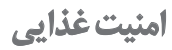

امنيت غذايى با مؤلفههايي نظير دفعات مصرف وعدههاى دوري غذايى، ميزان دسترسى به مراكز تهيه مواد خوراكى، دفئ دفعات

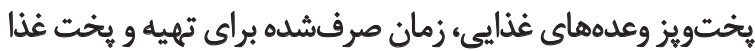

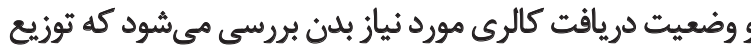
فراوانى اين متغيرها در جدول شماره بآ آورده شده است. امنيت غذايى به تدابيرى وابسته است كها از طريق آنها بتوان اقشار

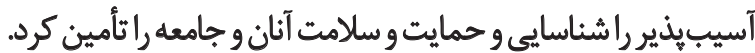

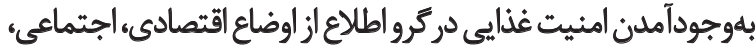

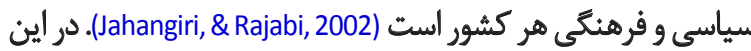

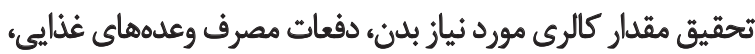

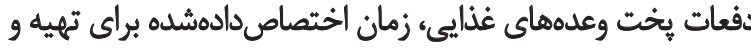

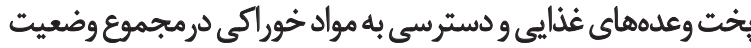

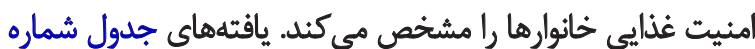

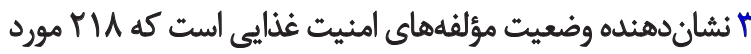

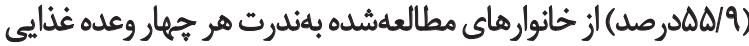

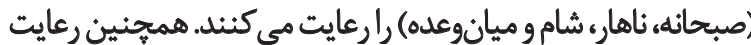

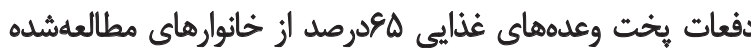
درحد برخىمواقع است. 
جدول F. توزيع فراوائى نكّرش شئاختى به مواد خوراكى در خانوارهاي مطالعهشده.

\begin{tabular}{|c|c|c|c|c|}
\hline مياتعين & درصد & ق قراوانى & دستهها & هؤلفه \\
\hline \multirow{5}{*}{ trRt } & $r / r^{n}$ & ir & بسياركم & \multirow{5}{*}{ للتتبردن ازز مواد غذايعي } \\
\hline & WD & $n$ & كم & \\
\hline & $r V / V$ & IFV & sis & \\
\hline & $T V / V$ & $1 \cdot 1$ & زياد & \\
\hline & $I T / A$ & Q. & بسيارزياد & \\
\hline \multirow{5}{*}{ 19/r9 } & $\mid f / 8$ & $\Delta r$ & بسياركم & \multirow{5}{*}{ تأثير غذا بر سلامتى } \\
\hline & $r \Delta / 1$ & Irv & كم & \\
\hline & $18 / \pi$ & RT & متوسط & \\
\hline & 1.10 & Pi & زياد & \\
\hline & $r \mu / g$ & 95 & بسيارزياد & \\
\hline \multirow{5}{*}{$P \& M$} & $\Delta / / T$ & r. & بسياركم & \multirow{5}{*}{ "مجموع" } \\
\hline & $F A / I T$ & IV & كم & \\
\hline & TNTK & 11. & هتوسط & \\
\hline & $\Delta / g r$ & r & زياد & \\
\hline & 1Q/9T & gr & بسيارزياد & \\
\hline
\end{tabular}

f. ميف مؤلفهها: 1 نا

1." ميف مجموع نكرش شناختى:

$$
\text { وخيلى ضعيف و با ميانگين كمتر از متوسط است. }
$$

فو فئك تثذايه

كميّت مواد غذايى در سودرصد از خانوارها براساس ائتخاب نوع

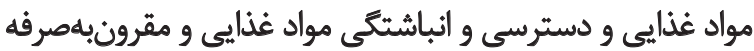
بودن انجام مى ميرد.

كيفيت مواد غنايي در • هدرصد از خانوارها در سطح كم و

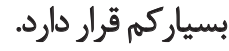

مصرف مواد غذايي حدود هذدرصد از خانوارها براساس سه سه

طبع كرم و سرد و معتدل در سطح ضعيفي قرار دارد.

بهطور كل مجموع كويههاي فرهنى تغذيه نيمى أز خانوارهاى مطالعهشده در سطح ضعيف و خيلي ضعيف قرار دارد كه ناشي موني

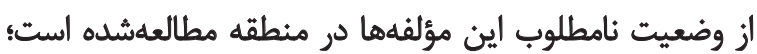

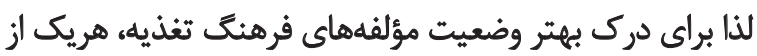

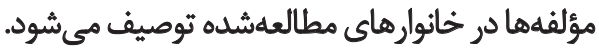

استنباطي

امنيت غذايي: دادهاي جدول شماره V نشان مي لهد ميانكين

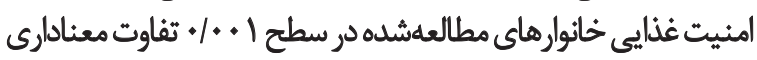

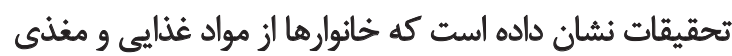

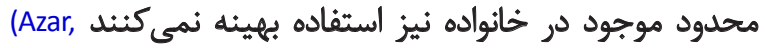
غذابع (1998).

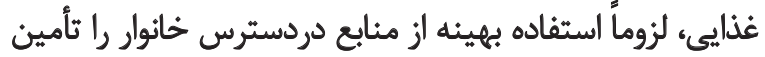

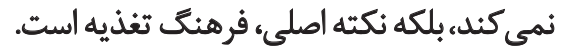

در اين مطالعه فرهنى تغذيه از جنبههاى يخت سالم، مواد غذايى سالمه، باورهاى غذايى، كميّت و كيفيت مواد غذايى بروسى شند توزيع فراواني وضعيت فرهنك تغذيه خانوارهاي مطالعهشده

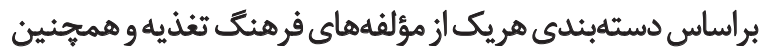

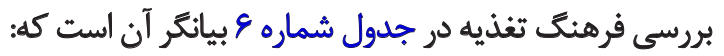

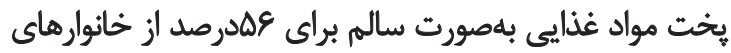
مطالعهشده ضعيف و خيلي ضعيف است. ميانكين اين مؤلفه نيز

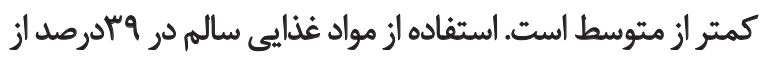

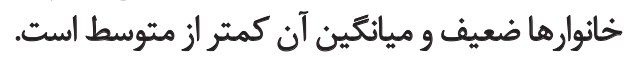
باورها و عادات غذايي در هددرصد از خانوارها در سطح ضعيف 
جدول ه. توزيع فراوانى نكرش رفتارى به مصرف مواد غذايى در خانوارهاي مورد مطالعه.

\begin{tabular}{|c|c|c|c|c|}
\hline مياتكين & ت ن مرصد & فراواتى & داستهol & 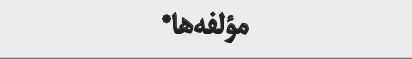 \\
\hline \multirow{5}{*}{$I V / r$} & $f / 9$ & 19 & بسياركم & \multirow{5}{*}{ قيمت مواد غذايى } \\
\hline & $1 . / 1$ & RT & s & \\
\hline & $M T / r$ & ir. & هتوسط & \\
\hline & $r+/ A$ & $|V|$ & زياد & \\
\hline & $V / r$ & rA & بسيارزياد & \\
\hline \multirow{5}{*}{ IV/OH } & IV/ & 99 & بسياركم & \multirow{5}{*}{ دردسترسبودن مواد غذايى } \\
\hline & QV & «A & كم & \\
\hline & $M V / F$ & $1 \cdot V$ & متوسط & \\
\hline & $M / \&$ & ITV & زياد & \\
\hline & $\mid r / 8$ & pq & بسيارزياد & \\
\hline \multirow{5}{*}{$M r / \Delta D$} & $1 . / 1$ & RT & بسياركم & \multirow{5}{*}{ عادت و رفتار اعضاى خاثواده به مواد غُناييى } \\
\hline & $r \cdot 1 \Delta$ & ᄉ. & S & \\
\hline & $\pi / A$ & १ั & متوسط & \\
\hline & repte & IfT & زياد & \\
\hline & NA & m & 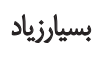 & \\
\hline \multirow{5}{*}{$\Delta V / \mathbb{R} A$} & $|r /|$ & p & بسياركم & \multirow{5}{*}{ هجموع" } \\
\hline & $p \varphi / q$ & IVD & كم & \\
\hline & $r F / F$ & $9 \Delta$ & متوسط & \\
\hline & $\Pi$ & rit & 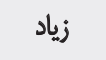 & \\
\hline & $V / V$ & r. & بسيارزياد & \\
\hline
\end{tabular}

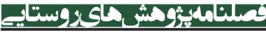

F. ميف مؤلفها:

Ir. FF Tf:

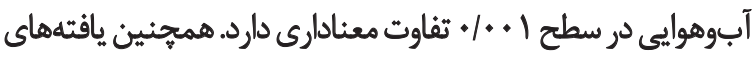

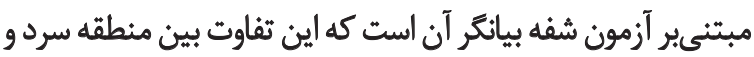

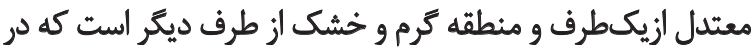

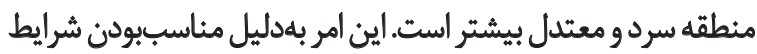

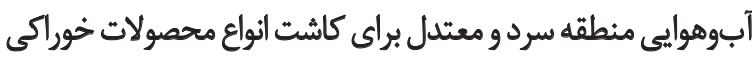

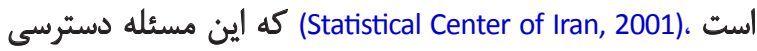

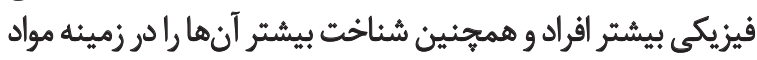

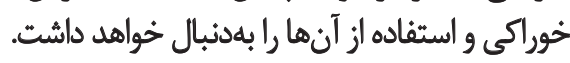

همجنين يافتههاى جدول شماره 9 نشاندهنده اين است

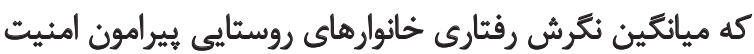

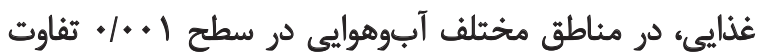

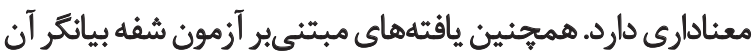

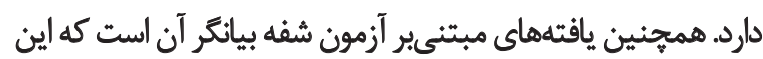

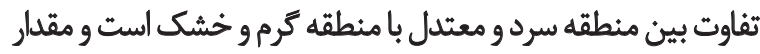

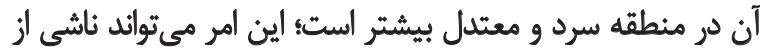

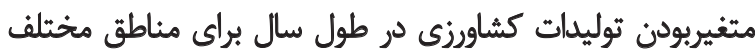

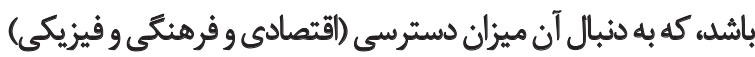

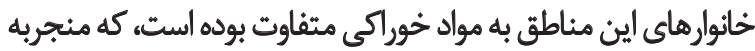

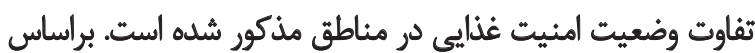

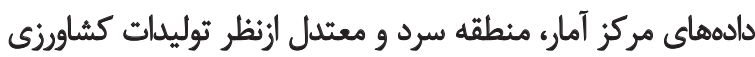

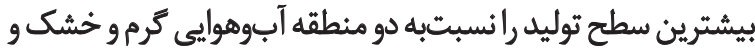
معتدل دارد (Statistical Center of Iran, 2001).

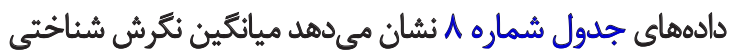
خانوارهاى روستايى نسبتبه امنيت غذايى، در مناطق مختلفي 
جدول 9. توزيع مؤلفههاى وضعيت فرهنك تغذيه خانوارهاي مطالعهشده.

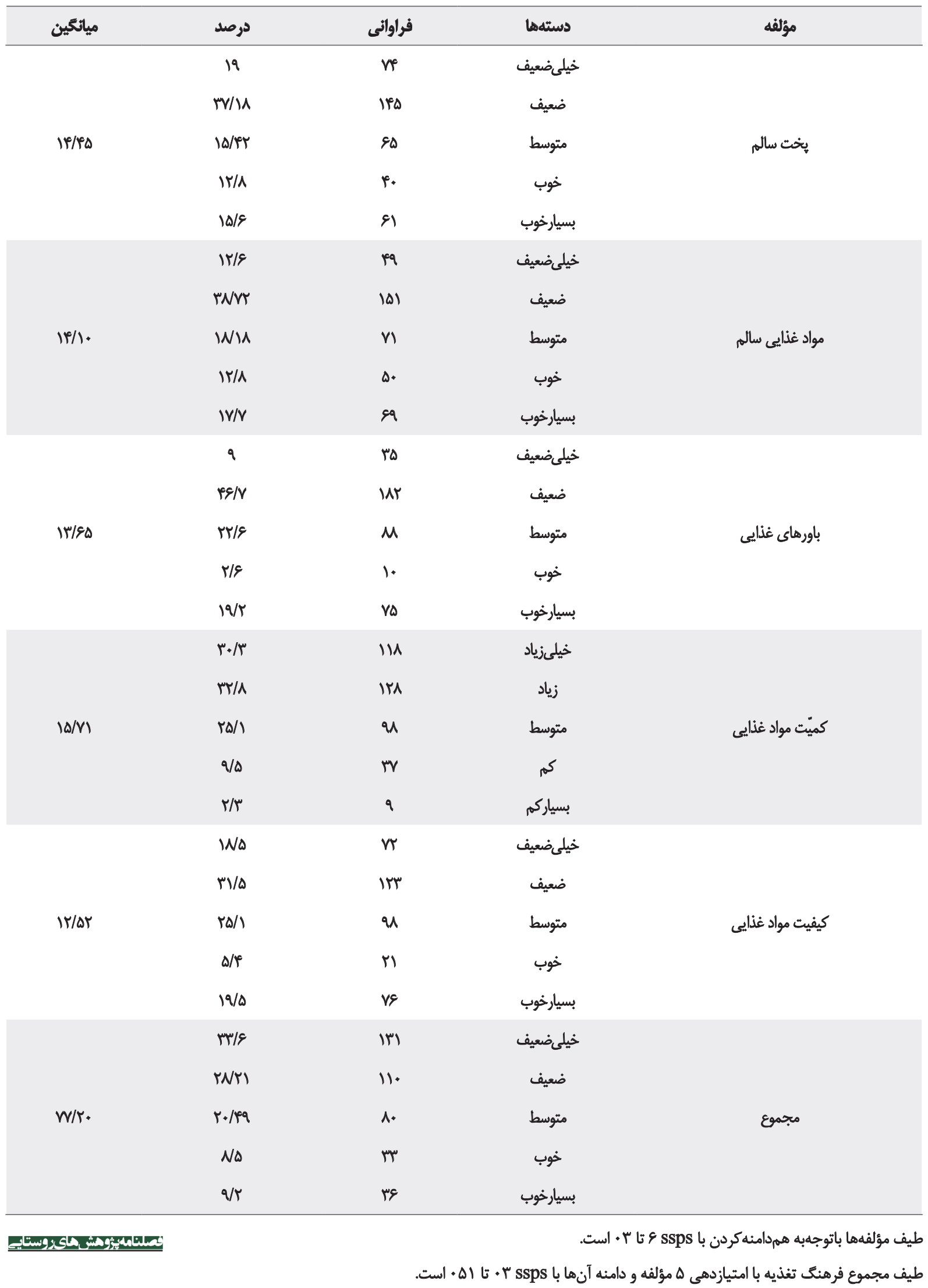


جدول V. مثايسه ميائكين (One-way Anova) امنيت غذايى خانوارهاي روستايى جنوب استان كرمان با مناطق مختلف آبوهوايى.

\begin{tabular}{|c|c|c|c|c|c|c|}
\hline Sig. & $\mathbf{F}$ & انحراف معيار & مياتعين" & 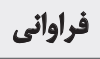 & مناطق مختلف آبوهوايى & مثغير وابسته \\
\hline \multirow{3}{*}{.10 .1} & \multirow{3}{*}{$1 . / 8 \pi$} & NEY & $M e / F T^{a}$ & iw & سرد و معتدل & \multirow{3}{*}{ امنيت غُذايهي } \\
\hline & & $V / V^{e}$ & $r \cdot p e r b$ & Mr & كرم و خشك & \\
\hline & & $1 \cdot 1 N$ & $P=/ A \cdot a b$ & $r$. & مestiv & \\
\hline
\end{tabular}

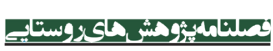

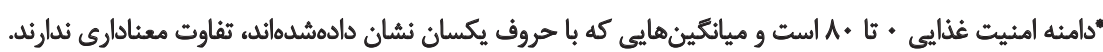

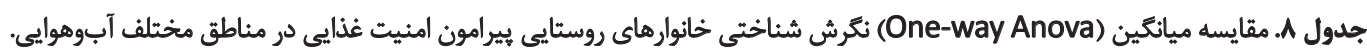

\begin{tabular}{|c|c|c|c|c|c|c|}
\hline Sig. & $\mathbf{F}$ & انحراف معيار & مياتكين" & فراوائى & مناطق مختلف آبوهوايى & متغير وابسته \\
\hline \multirow{3}{*}{.10 .1} & \multirow{3}{*}{1.14.} & $11 / M$ & er/ega & in & سردو معتدل & \multirow{3}{*}{ نكرش شناختى } \\
\hline & & $1 . / 0 r$ & $\Delta V / M r^{b}$ & Mr & كرم وخشى & \\
\hline & & $10 / \pi V$ & $\mathbb{N} \cdot r^{\mathrm{ab}}$ & r. & معتل & \\
\hline
\end{tabular}

در مناطق مختلف باشد. آمار توليدات كشاورزى جنوب كرمان

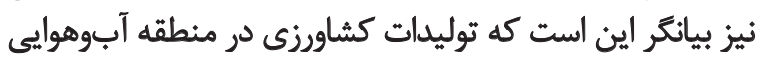
سرد و معتدل بيشتر است (Ministry of Agriculture, 2010).

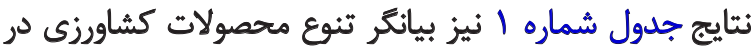

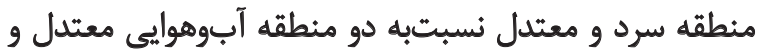

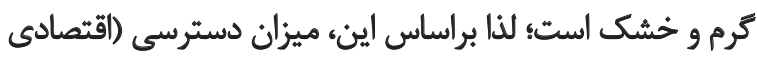

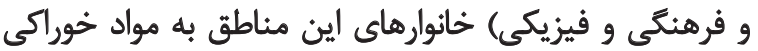

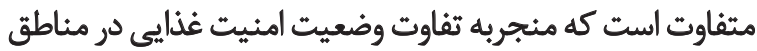

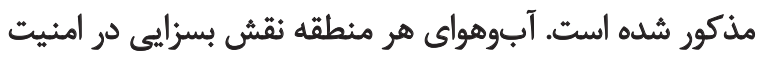

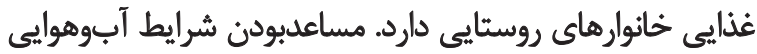

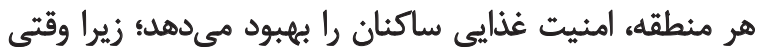

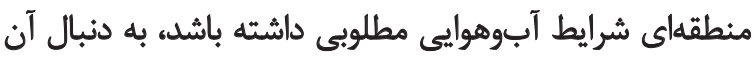

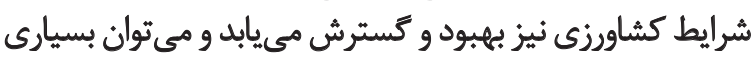

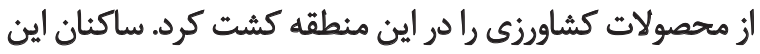

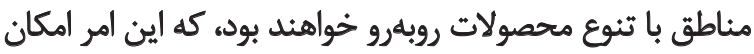

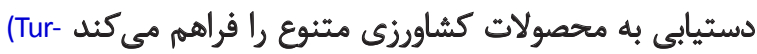

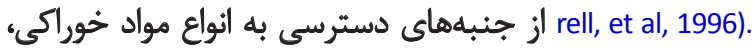
دسترسى فيزيكى است، كه شامل موجودبودن مواد خوراكى در انر
است كه اين تفاوت بين منطقه سرد و معتدل با دو منطقه ديكر

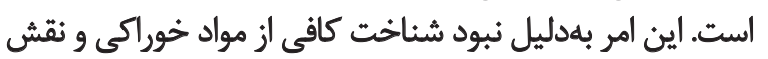

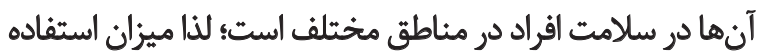

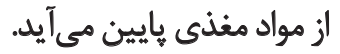

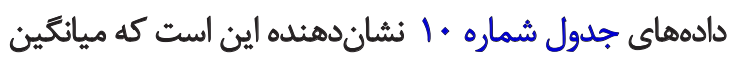

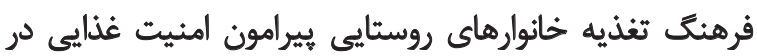

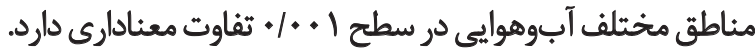

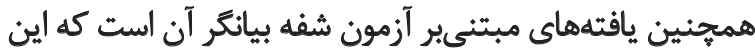

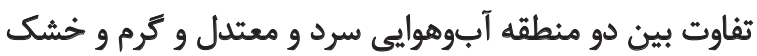
است كه در منطقه سرد و معتدل بيشتر است است

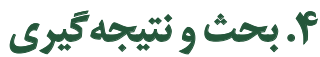

وضعيت فعلى امنيت غذايى خانوارهاى مطالعهشده بيانكر

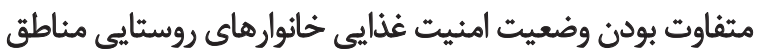

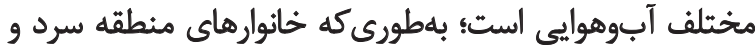

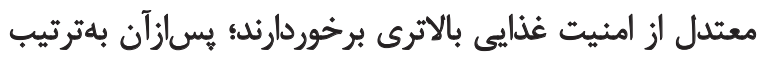

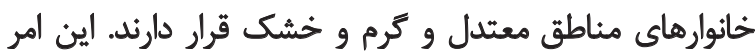

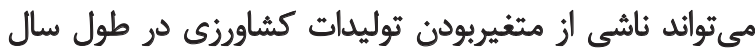

جدول 9. مقايسه ميانكين (One-way Anova) نكرش رفتارى خانوارهاي روستايع يُيرامون امنيت غذايع در مناطق مختلف آبوهوايى.

\begin{tabular}{|c|c|c|c|c|c|c|}
\hline Sig. & $\mathbf{F}$ & انحراف معيار & ميانكين & فراواتى & مناطق مخثلف آبوهواييى & متغير وابسته \\
\hline \multirow{3}{*}{$.1 .+1$} & \multirow{3}{*}{$1 . / 1 A \Delta$} & IV/AT & $A+/ f^{2} a$ & in & سرد و معتدل & \multirow{3}{*}{ نكرش رفتارى } \\
\hline & & $\mid F / M$ & VNI $9^{\mathrm{b}}$ & Mr & كرم و خشك & \\
\hline & & IE/AV & $n / F \cdot b$ & $r$. & هestes & \\
\hline
\end{tabular}


جدول •ا. مقايسه ميانكين (One-way Anova) فرهنَ تغذيه خانوارهاي روستايى ثيرامون امثيت غذايى در مناطق مختلف آبوهوايى.

\begin{tabular}{|c|c|c|c|c|c|c|}
\hline Sig. & $\mathbf{F}$ & انحراف معيار & مياتكين" & 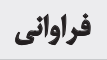 & مناطق مختلف آبوهوايى & مثغير وابسئه \\
\hline \multirow{3}{*}{.1 .01} & \multirow{3}{*}{ NIT } & $\mid r / 4$ & $\Lambda r / q Y^{a}$ & in & سرد و معتدل & \multirow{3}{*}{ فرهنك تغذيه } \\
\hline & & $11 / 4 e^{2}$ & VNAY & Mr & كرم وخشك خ & \\
\hline & & 18/9Y & $W / A^{a b}$ & r. & هعتدل & \\
\hline
\end{tabular}

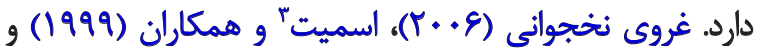

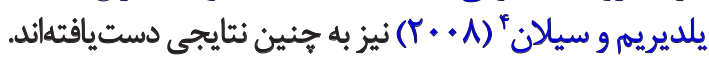

در جنين وضعيتي فرهنئ تغذئيه خانوارهاي روسيتايي در

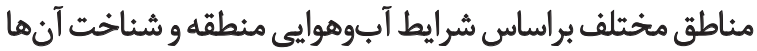

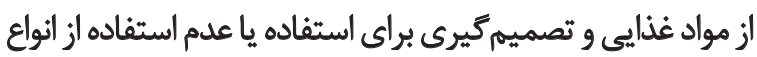
مواد غذايى تأثير مي يذيرد (Azar, 1998).

فرهنك تغذيه هرمنطقه با شرايط حاكم بر آن منطقه وابستكي

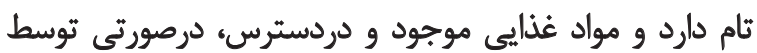

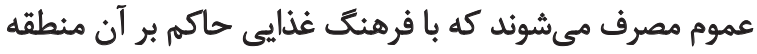

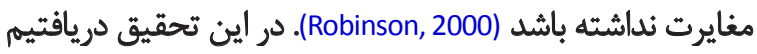

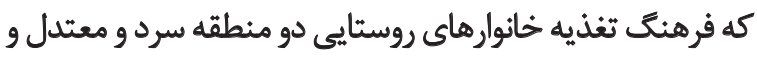

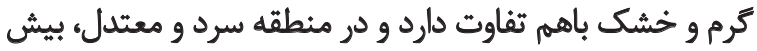

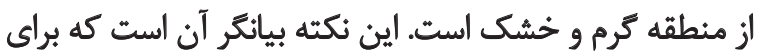

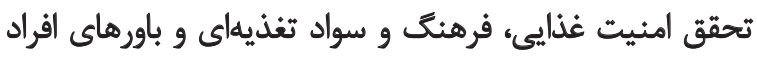

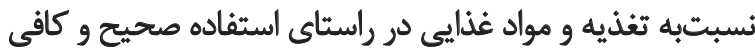

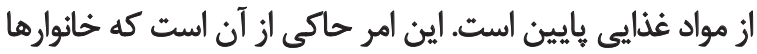

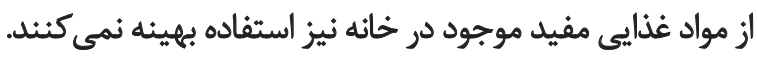

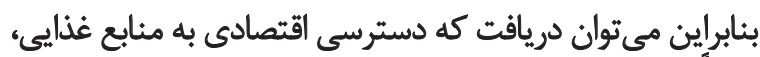

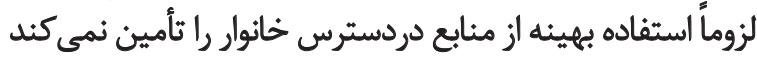
بلكه عامل اصلي فرهنَ تثغذيه است (Azar, 1998).

نتايج اين مطالعه بيانكر متفاوتبودن وضعيت امنيت غذاييى

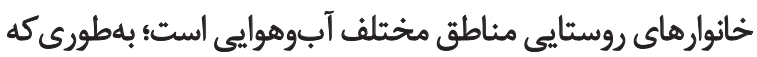

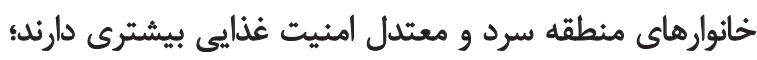

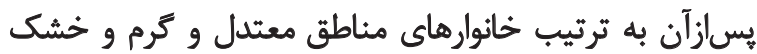

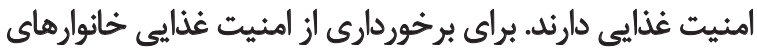

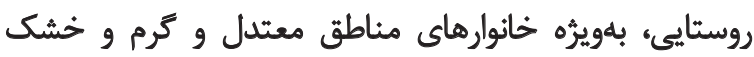
ييشنهادهاى زير مطرح مي بـون:

تنوع بخشيدن به الكوى زراعي منطقه با ترويج كشت مئت

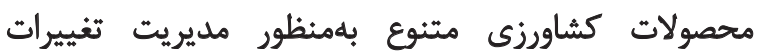

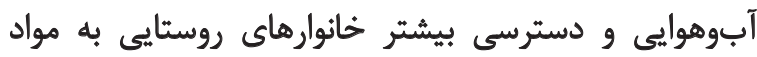

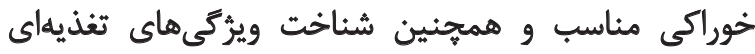

3. Smith

4. Yildirim and Ceylan
منطقه است (Smith, Amani, \& Jensen, 1999). در منطقه مطالعهشده در اين يرؤهش، خانوارهايي كه براساس

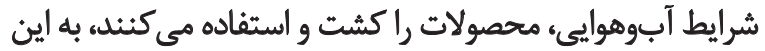

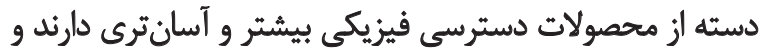
بالعكس؛ در مناطقى كه توليدات كشاورزى محدود است، ميز فيزان دسترسى فيزيكى به برخى محصولات نيز كمتر است، كهاين مسئله

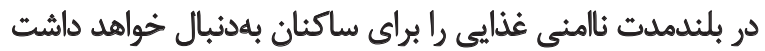
(Bickel, Nord, Price, Hamilton, \& Cook, 2000).

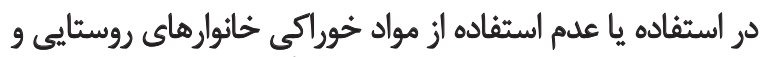

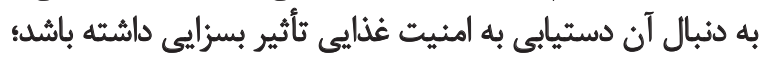

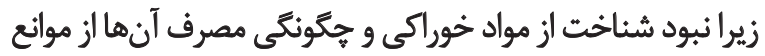

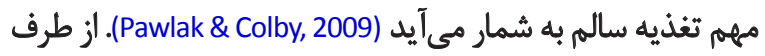

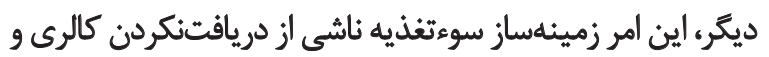

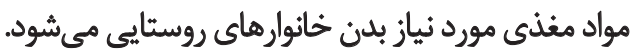
در اين تحقيق درياقتيم نكرش شئاختى افراد در دو منطقه

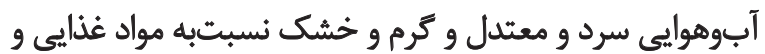

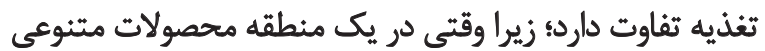

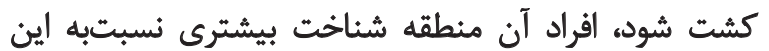

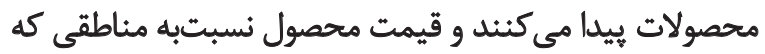

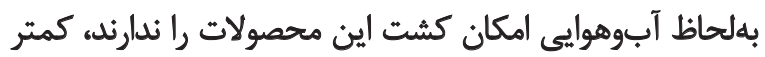

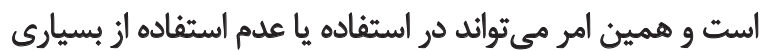

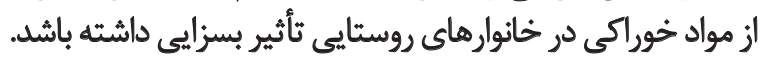
براساس دادههاي هركز آمار، منطقه سرد و معتدل ازئظر توليدات

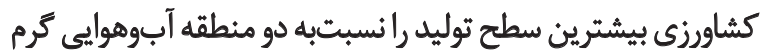

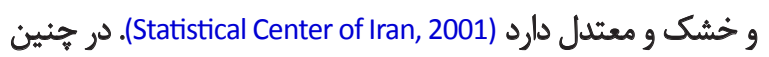

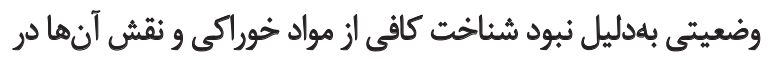

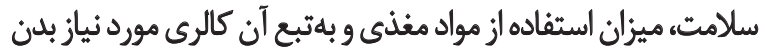

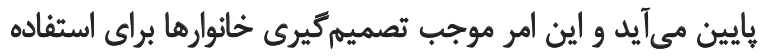

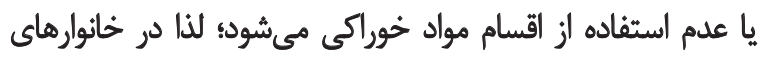

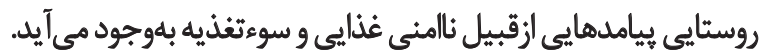

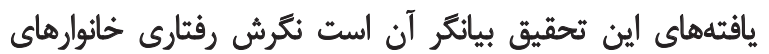

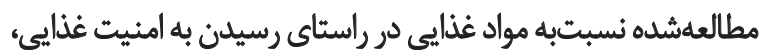

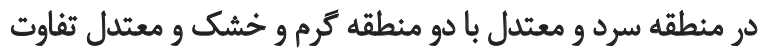




\section{References}

[The southern part of Kerman province is still grappling with poverty and deprivation (Persian)]. (2010). Retrieved from http://www.halil. ir/fa/ew_news_2664.ashx

Akhondi, M. (2008). [A look at food and nutrition from Islamic perspective (Persian)]. Hasoon, 15, 175-90.

Azar, M. (1998). [Food and nutrition security: the security of the operation (Persian)]. Tehran: Tehran University Press.

Bakhtiari, S., \& Haghi, Z. (2003). [Investigation of food security and human development in Islamic countries (Persian)]. Journal of Agricultural Economics and Development, 11(43, 44), 21-52.

Behroozeh, S. (2014). [Explaining the Islamic-Iranian food security model: South villages of Kerman province (Persian)] (MA thesis). Shiraz: Shiraz University.

Bickel, G., Nord, M., Price, C., Hamilton, W. L., \& Cook, J. (2000). Guide to measuring household food security. Washington, D. C.: United States Department of Agriculture.

Center of Kerman Studies. (2000). [Kerman at a glance (Persian)] (1 $1^{\text {st }}$ ed.). Kerman: Center of Kerman Studies Publication.

Environment News. (2013). [The impact of climate change on life on earth (Persian)]. Retrieved from http://www.asriran.com/fa/ news $/ 267300$

FAO. (2002). Report of the World Food Summit: Five years later (1st ed.). Rome: Food and Agriculture Organization of the United Nations.

Galal, O. (2003). Nutrition-related health patterns in the Middle East. Asia Pacific Journal of Clinical Nutrition, 12(3), 337-43.

Ghaderpoor, Y. (2007). [Feeding place in the culture of the Kurdish people from the perspective of anthropology (Case study: city of Bukan) (Persian)] (MA thesis). Hamadan: Bu Ali Sina University.

Ghahraman, N., \& Mahdavian, A. (2014). [Human food security challenges and the need for climate models using the product (Persian)]. Hamadan: Meteorological Organization of Hamedan Province.

Gharavi Nakhjavani, S. A. (2006). [The poverty of Iranian households during the last Two decades (Persian)]. Social Welfare Quarterly, 5(17), 93-118.

Ghasemi, H. (1995). [Theoretical basics and definitions of food security (Persian)]. Tehran: Agricultural Planning, Economic and Rural Development Research Institute.

Ghazali Jahromy, T. (2012). [Human and climate impact on him (Persian)]. Retrieved from: http://ghazalii.blogfa.com/post-52.aspx

Ghias, M., Seidaei, A., Taghdisi, A., Roozbehani, R., Poursafa, P., Barghi, H., et al. (2000). [The impact of weather on some psychological and behavioral disorders among 4-7-year-old children in rural area of Isfahan province according to medical geography (Persian)]. Journal of Isfahan Medical School, 28(122), 1745-751.

Ghodrat, R. (2005). [The study of knowledge and practice of health workers in primary schools in Kerman toward nutritional status in 1382 (Persian)] (PhD thesis). Kerman: Kerman University of Medical Sciences.

Herzberg, S. (1993). Nutrition and public health from the perspective of epidemiology and prevention policies [A. Keshavarz, (Persian trans.)]. Tehran:: Tehran University Publication.

News Station and Analysis of Kerman Province (Halil). (2011,
محصولات كشاورزى براى بهبود تغذيه اعضاى خانوار؛

تخصيص يارانه خريد مواد غذايى براي مناطق روستايي با بإنائ

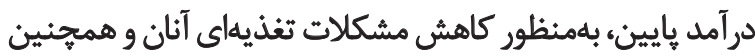

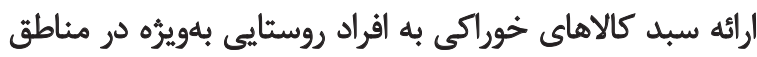

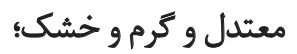

ايجاد بازارجههاي محلى براي دسترسى بيشتر روستاييان به

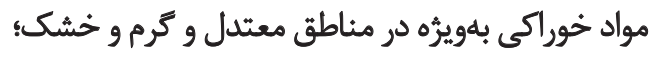

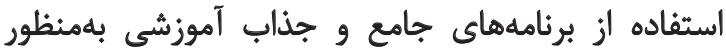

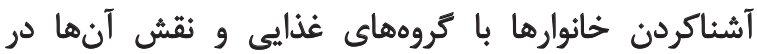

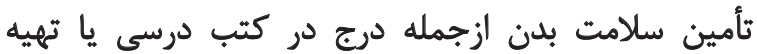

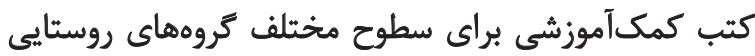
بلمنظور ارتقاى سطح آكاهي درزمينه تنذيه؛

اجراى مداخلاتى مبتنى بر شواهد و براساس مبانى آموزش تغذئيه،

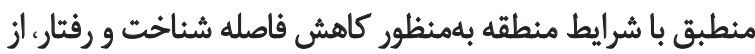
طريق آموزش در راديو، ثلويزيون، مدارس و نصب يُ يوستر در روستاهاء لزوم توجه به فرهنكَ تغذيه خاص هر منطقه و بهبود آن بابركزارى كلاس هاى ترويجى آموزشى بهتناسب مخاطبان مناطق آبوهوروايى.

$$
\text { تشكر و قدردانى }
$$

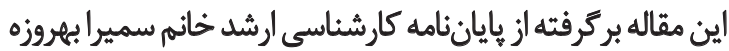

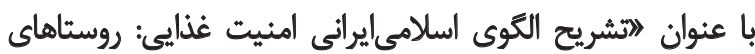

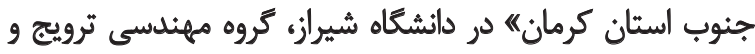

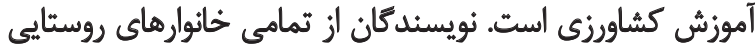

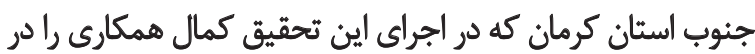
تكميل يرسشنامه داشتند، قدردانى مى كنيند. 
November 29). [The southern part of Kerman province is still grappling with poverty and deprivation (In Persian)] [Internet]. Retrieved from http://www.halil.ir/fa/ew_news_2664.ashx. Date of publication: November 29, 2011.

Jahangiri, J., \& Rajabi, M. (2002). [Investigation of culture and nutritional literacy among women of Shiraz (Persian)]. Journal of Social Sciences, 16(2), 75-97.

Kamkar, B., \& Mahdavi Damghani, A. (2007). [Principles of sustainable agriculture (Persian)] ( $1^{\text {st }}$ ed.). Mashhad: Ferdowsi University of Mashhad.

Kerjcie, R. V., \& Morgan, D. W. (1970). Determining sample size for research activities. Educational and Psychological Measurement, 30(3), 607-10. doi: 10.1177/001316447003000308

Kurz, M. K., \& Johnson-Welch, C. (2001). Enhancing women's contributions to improving family food consumption and nutrition. Food and Nutrition Bulletin, 22(4), 443-53.

Malick, D., \& Rafi, M. (2009). Are female-head household more food insecure? Evidence form Bangladesh. World Development, 38(4), 593-605. doi: 10.1016/j.worlddev.2009.11.004

Matheson, D. M., Varady, J., Varady, A., \& Killen, J. D. (2002). Householdfood security and nutritional status of Hispanic children in the fifth grade 1,2 and 3. American Journal of Clinical Nutrition, 76(1), 210-17. PMID: 12081837

Melgar-Quinonez, H., Zubieta, A., Mknelly, B., Nteziyaremye, A., Gerardo, M., \& Dunford, C. (2006). Household food insecurity and food expenditure in Bolivia, Burkina Faso, and the Philippines. Journal of Nutrition, 136(5), 1431-437. PMID: 16614440

Ministry of Agriculture. (2010). [Agricultural statistics (Persian)]. Retrieved from www.http://amar.maj.ir/Portal/Home/Default. aspx?CategoryID=117564e0-507c-4565-9659-fbabfb4acb9b

Mohseni, M. (2006). [Medical sociology (Persian)] ( $8^{\text {th }}$ ed.). Tehran: Tahoori Publication.

Moshfegh, Zh. (2002). [Examine the functioning of the cartoon in the city of Shiraz Jihad Agriculture Organization experts attitude change towards sustainable agriculture (Persian)] (MA thesis). Shiraz: Shiraz University.

Nord, M., \& Parker, L. (2010). How adecuately are food needs of children in low-income hoseholds being met? Journal of Children and youth Services Reviev, 32(9), 1175-185. doi: 10.1016/j.childyouth.2010.03.005

Nord, M., Andrews, M., \& Carlson, S. (2009). Measuring food security in the U. S: Hosehold food security in the United States, 2008. Washington, D. C.: United States Department of Agriculture.

Ouetlette, J. A., \& Wood, W. (1998). Habit and Intention in Every Day Life; The multiple processes by which past behavior predict future behavior. Journal of Nutrition Psychonomic Bulletin, 124(1), 54-74. doi: 10.1037//0033-2909.124.1.54

Papi, A. (2015). [Its natural environment and climate cultured people (Persian)]. Retrieved from http://vista.ir/article/314420

Pawlak, R., \& Colby, S. (2009). Benefits, barriers, self-efficacy and knowledge regarding healthy foods; perception of African Americans living in eastern North Carolina. Journal of Nutrition Research and Practice, 3(1), 56-63. doi: 10.4162/nrp.2009.3.1.56

Robinson, K. H. (2000). Nutrition principles [V. Khaldi, (Persian trans.). Tehran: Salemi Publication.
Salarkia, N., Amini, M., Abdollahi, M., \& Eshrati, B. (2000). [Socioeconomic and cultural factors affecting child feeding practices: Anexploratory qualitative study in Damavand (Persian)]. Iranian Journal of Nutrition Sciences \& Technology, 5(4), 75-86.

Shafaghi, S. (2005). [Isfahan of Geography (Persian)]. Isfahan: Isfahan University Press.

Smith, L. C., Amani, E. L., \& Jensen, H. H. (1999). The geography and causes of food insecurity in developing countries. Journal of $\mathrm{Nu}$ trition Agricultural Economics, 22(2), 199-215. doi: 10.1111/j.15740862.2000.tb00018.x

South Kerman Aricultural and Natural Resources Research and Education Center. (2014). The introduction of Jiroft [Internet]. Retrieved from http://jiroft.areo.ir/HomePage. aspx?TabID=9995\&Site=jiroft.areo\&Lang=fa-IR

Statistical Center of Iran. (2001). [Directory actuaries. Project cost and household income in 1379 (Persian)]. Retrieved from http://www. amar.org.ir/Default.aspx

Taghavi Shirazi, M. (2004). [Nutrition (Persian)]. Journal of Health, 2, 381-98.

Turrell, G. (1996). Structural, material and economic influences on the food- purchasing choices of socioeconomic groups. Australian and New Zealand Journal of Public Health, 26(6), 611-617. doi: 10.1111/j.1467-842x.1996.tb01075.x

Yildirim, I., \& Ceylan, M. (2008). Urban and rural households fresh chicken meat consumption behaviors in Turkey. Journal of Nutrition Nutrition and Food Science, 38(2), 154-63. doi: $10.1108 / 00346650810863037$ 